\title{
Why look at life courses in an interdisciplinary perspective?
}

\author{
René Levy and the Pavie Team ${ }^{1}$
}

\section{Challenges of life-course research}

After decades of a rather marginal existence and little coherence in its development, lifecourse research is definitely coming of age. There are, however, recent signs of consolidation and first attempts at reaping the scattered harvest of research in various disciplines, especially in the form of a first handbook of life-course research (Mortimer \& Shanahan, 2003), of first attempts at interdisciplinary dialogue around specific approaches such as Baltes' life-span psychology ${ }^{2}$ (Staudinger \& Lindenberger, 2003) and of a specialized annual review (in which this volume is published). Nevertheless, life-course scholars still seem to be a small handful « digging » on the fringe of their disciplinary mainstreams, as yet with little influence on more established fields of research. Why are we, i.e., life course researchers, so keen on life courses? What is there so special about life-course research? We feel in fact that are a number of specific challenges life-course researchers have to confront and to answer.

A first, global and not very differentiated reason for finding it particularly interesting could be that it encompasses all we find important about human life, that everything humanly relevant is in the life course.

A second answer, of the same global kind but a bit more specific, could be that only a lifecourse approach takes fully into account the fact that our lives are ongoing processes and not just single states or events that can be adequately captured and understood using snapshots.

\footnotetext{
${ }^{1}$ The Pavie Team, as it existed when the interdisciplinary venture that produced this volume was launched, comprised a founding group of six professors and eight researchers and research assistants. They all participated in the elaboration of a working document that was the basis of an international colloquium held in october 2003 and that has been largely integrated into this introduction. In order to underscore the team character of this work, we list their names in strict alphabetical order: Jean-Claude Deschamps, Guy Elcheroth, Yannic Forney, JacquesAntoine Gauthier, Paolo Ghisletta, Jean Kellerhals, Christian Lalive d'Epinay, Jean-Marie Le Goff, René Levy, Anik de Ribaupierre, Claudine Sauvain-Dugerdil, Dario Spini, Manuel Tettamanti, Eric Widmer.

${ }^{2}$ Coming from two - at times - different scientific traditions, the terms life course and life span share so much meaning at many levels (conceptual and methodological) that we can safely focus on the similarities between the two terms and consider them as basically synonymous. Instead of using them interchangeably, we rather settle on the use of life course for the sake of simplicity (for a discussion of these two terms, along with the less adequate one of life cycle, see Settersten, 2003a who takes the same terminological stand as we do).
} 
A third reason of attractiveness, even more fascinating but also demanding, is the crosscutting and integrative nature of the life-course perspective with respect to most of our more conventional, institutionalized disciplinary specialties. To illustrate this statement, take the case of sociology. ${ }^{3}$ There are special sociologies of childhood, of youth or adolescence, (maybe soon also of post-adolescence,) of retirement, of aging. Each « age group » is treated in a more or less static perspective and therefore reified as a somehow homogenous social category and not as a phase in the process of life course unfolding. There are special sociologies of the family, of work, of labor markets, of leisure, of stratification and mobility, of voluntary associations, of social movements and so on. Each social field is mainly treated as an isolated entity with its inner logic and specific pathways for the individuals who participate in these fields. Life-phase specific and sector specific sociologies have developed their specialized perspectives, slicing up the lives and contexts of the " whole individuals » we pretend to be into various aspects, types of social relations, phases or fields of action. Likewise, in psychology, ontogeny has by many been regarded as occurring almost differently in distinct fragments of the life span. Much as in sociology, the American Psychological Association, among its 53 divisions, has Division 7 for Developmental Psychology and Division 20 for Adult Development and Aging. Similarly, Division 12 is for the Society of Clinical Psychology, while Division 53 for the Society of Clinical Child and Adolescent Psychology. Again, the fragmentation of the life course has been, for some aspects at least, institutionalized. Against this reductionistic, fragmenting tendency, Settersten (2003b: 196) has rightly made a strong point of « The importance of understanding people in whole (over time) and as wholes (studying larger profiles of traits and characteristics rather than single variables) ». Without an encompassing perspective, life-course research cannot meet the challenge of its very raison d'être.

On a more fundamental level, there is a fourth challenge which is already included in these remarks but not explicitly spelled out : life-course analysis is one of the rare ways social sciences have developed so far to conceptualize time not just as a physical happening whose whereabouts escape our theoretical understanding, but as something that is culturally, socially and also individually molded, reworked, « constructed », something that has both a subjective and an objective existence, and whose very objectivity is the result of social objectivation rather than of mere «being there » like the eternal rhythm of atomic oscillation. Settersten (1999) has entitled his recent stock-taking book «Lives in Time and Place », referring to two basic dimensions of the real world that both are not just physical « givens », but socially con-

\footnotetext{
${ }^{3}$ An entirely parallel argument could be made for psychology and probably other disciplines of the social sciences.
} 
structed: social space and social time. In classical developmental psychology, most research was concerned with charting along the age axis the newly acquired skills and mastered developmental tasks by children. Refined descriptions of what the child could achieve at what age flourished, and in various domains age-related norms were established. Wohlwill (1970) was one of the first questioning the limitations of the mere descriptive role of chronological age. (We shall take up the question of what status to give to age in our theorizing about life courses in the final chapter.)

In short, in both a humanistic and in a scientific view, life-course research is fascinating because it forces us to break down traditional limitations of understanding.

\section{The necessity of interdisciplinarity}

If adopting a life-course perspective in a single study does not exclude focusing on a specific aspect of peoples' lives, the perspective as such is necessarily integrative: it has to bridge a number of institutionalized chasms in and between social science disciplines. These chasms are sometimes openly discussed, even questioned, sometimes rather taken for granted. At any rate they tend to limit our awareness, inducing what we may call an internalistic perspective, artificially bounded by the boundaries of the specialty in which our scholarly activity is organized. We have already mentioned two dimensions life-course researchers have to bridge in their work, the age-group axis and the life-spheres axis. At least three others are of equal importance:

- what sociologists, and others as well, are used to call the macro-micro link, i.e., more generally, the fact that one basic dimension in the complexity of reality is the nesting of encompassing systems of various levels ${ }^{4}$; this dimension (we might call it systemic differentiation to distinguish it from two others, hierarchization or parallelism) takes all its importance in the debate about the institutionalization of life-course patterns as opposed to actorial agency although it is more often invoked as important than really taken into account,

\footnotetext{
${ }^{4}$ On can lead lenghty discussions about the proper use of terms like macroscopic or microscopic - what is micro for a sociologist may be very macro for a psychologist, what is micro for a psychologist may be way underneath the systemic level for which other social sciences have analytical resources. Instead of doing this, let us just illustrate the notion of encompassing system levels by citing three examples in ascending order : different psychological systems (like memory, emotion, etc.) - interindividual interactions - relations between social institutions (e.g., in organizing subsequent or simultaneous stages of the life course).
} 
- gender differences or more generally the social relationships between the sexes, ${ }^{5}$ but also a number of other cases of strong social differentiation of both a cultural and a structural kind that have strong incidences on the level of individual identities (like ethnic or religious group membership etc.), that are often leveled out by static analyses or even ignored by gender-blind or more generally « differentiation-blind » theoretical models, ${ }^{6}$

- linked lives, the strong interdependencies between the life courses of related persons that remind us that the real object of most of the social sciences are relations between actors and not just monadic individuals as some current mainstream paradigms would have it. ${ }^{7}$

If we are to bridge successfully all these gaps, with their thematical, conceptual and methodological implications, one may object that we have to become scientific geniuses. As social scientists we know that individual mastery is not all, that groups are frequently wiser than the « addition » of their individual members, so team-work is certainly a way out of this problem. Working integratively in the sense just mentioned calls for team work.

Among the gaps that work on life courses intrinsically needs to bridge figures also the one between scientific disciplines, above all in the social sciences (including, of course, psychology). The arguments for interdisciplinarity in this area may not be fundamentally different from those applying to other themes - as soon as we get interested in a real world problem and not only an epistemological slice of it, we can not be satisfied by adopting one disciplinary perspective only. Most often, interdisciplinarity is claimed for problem-oriented or « applied » research. If the research objective is to resolve a problem, disciplinary purity and coherence is of no interest, we mobilize all promising resources whatever their disciplinary origin and theoretical ramifications. This may not be the primary orientation of life-course research. But there is another important and sufficient motive for interdisciplinarity in this area that we have already encountered: the holist perspective on individuals and their development in social context which cannot be contented by any single aspect alone, be it sectoral

\footnotetext{
${ }^{5}$ This is an uneasy translation of the standard French expression « rapports sociaux de sexe ».

${ }^{6}$ It goes without saying that a similar argument could be made for all classical sociological variables supposed to capture some aspect of social differentiation, first of all «class » or position in social hiearchies, but several of these are socially less « thick ». We do, of course, not mean to relegate them to a secondary position for analysis, but rather feel that in current research, there is a danger of too exclusive a concentration on them.

${ }^{7}$ The most general paradigm of this sort in sociology is rational choice theory or « methodological individualism ». But there are many more specialized areas where predominant approaches at least implicitely adopt an individualist stance, for instance in the form of the status attainment paradigm in mobility research. In psychology, the same problem exists but in a more fundamental sense, considerations of « contextuality » being more intrinsically out of theoretical bounds than, say, in sociology, social psychology or political science (but see Bronfenbrenner's ecological model, 1979, Baltes' contextualism, Baltes, Lindenberger \& Staudinger, 1998, or even Erikson's epigenetic model, 1950).
} 
or disciplinary. It is no accident that interdisciplinarity is frequently called for in this area. When formulating his « life-course paradigm », Elder (1995) included interdisciplinarity explicitly, but the overriding research praxis remains monodisciplinary. ${ }^{8}$

A further question is then: what should we mean by interdisciplinarity? We usually use the term in a very general sense, meaning just going beyond the limits of any one of our usual disciplines (mono-disciplinarity). In order to be more precise, we may join an emergent distinction between

Multidisciplinarity (or pluridisciplinarity), meaning the cooperation of several disciplines that work on complementary aspects of a common overall question,

interdisciplinarity, meaning the integrated cooperation of disciplines on the basis of common concepts,

transdisciplinarity, meaning the scientific work on the basis of common concepts that do not belong to any specific discipline and that may also include the points of view of extra-scientific actors concerned by the question under study. ${ }^{9}$

There is no general, absolute value hierarchy to be established between these possibilities, « trans » is not necessarily better than « multi » and there may very well be problems whose «mono» study is quite adequate. The proper level between mono- and transdisciplinarity must be identified for each research enterprise, and the optimum may very well be an evolving mix and not a one-level solution fixed once and forever. But what is certainly necessary is the capacity of people and teams to work on these different levels. In order for such an enterprise to work, a more or less clearly stated common goal is of course essential, but other conditions are of equal importance: the real desire of the participants to work together, their acknowledgement of the potential of mutual learning rather than competition, even less the pursuit of disciplinary hegemony, and a fundamental working knowledge allowing for an understanding and appreciation of the conceptual and methodological panoply of neighboring disciplines.

\footnotetext{
${ }^{8}$ There are some special research fields where interdisciplinary is already practised in a more or less regular way, such as gerontoloy. But even here, collaboration is often more of a coordinated parallelism than real cooperation. Moreover, in this case, research is not systematically placed in a full life-course framework.

${ }^{9}$ Some authors suggest that the vocabulary of truly transdisciplinary analysis should be based outside the boundaries of scientific terminology. This may be useful in highly problem-oriented research, but should not be seen as a general rule. Systems theory provides a scientific vocabulary for transdisciplinary conceptualization that is, to the least, no less promising than everyday or other non-scientific language.
} 
There is a huge gap between the almost unisonous choir of public voices asking for interdisciplinarity, and scientific everyday practice which is needed to discover the real difficulties of such an endeavor to begin with. A realistic approach must probably start from the principle that with a view to interdisciplinary convergence or at least cooperation, differences should not be silenced, but discussed and integrated. Well-placed protagonists assure us that this is no easy business - witness, as one example, Mayer (2002) who coolly states on the encounter of life-course sociology and life-span psychology (in which he has been engaged himself) : «In retrospect, despite all the strong mutual recognition and reinforcement, surprisingly little convergence and integration has actually occurred. ». There is definitely still some way to make; the present volume is meant to bring us a step ahead on this way.

\section{Difficulties of interdisciplinarity}

As long as not many social scientists have themselves a really interdisciplinary education and working profile, interdisciplinary work is bound to be teamwork. Along with more current organizational questions, interdisciplinary teams have to confront quite real problems in their everyday functioning, even if these may often seem somewhat trivial when looked at from a theoretical vantage point. These practical difficulties need to be taken seriously in order to overcome them. Let us briefly look into some of them. But an assured rootedness in their own disciplines of scholars working together in an interdisciplinary team is most probably a precondition for successful interdisciplinarity, even though this may appear as a paradox.

A first kind of difficulties to be clarified and surpassed on the way to interdisciplinary teamwork is in the area of vocabulary. Our disciplines use some identical terms with quite different meanings (e.g., « norm» has an entirely cultural, obligational ring in sociology, but the objectivist meaning of statistical prevalence - or even biological « normality » - in developmental psychology; or the different semantic extension of the notion of « micro » and « macro » between the same two disciplines). The other way round, we use sometimes different terms for the same things (e.g. in the methodological area). One example seems to pose little problem: the more sociological or demographical term of life course seems to overlap very largely with the more psychological one of life span. We therefore consider them in this chapter as synonyms. Another, probably minor, example are different names used in different disciplines for the same methods (e.g., survival analysis, event history analysis, or, in French, 
« demographical analysis of biographies ${ }^{10}$ in the current terminology of demography all designate the same or at least highly similar analytical methods; the same is true for multilevel models - random effect models - mixed effect models and also hierarchical models).

Other differences, that cannot be ruled out by mere lexical agreements, are related to the typical frames of attention of the disciplines. Mainstream (or traditional) developmental psychology focuses largely on very early (and, to a lesser extent, very old) years of life while the bulk of sociological work concerns the adult years (mostly without spelling out explicitly this horizon). At first sight, social psychology does not seem to be very specific in this respect; in fact, it shows only rarely an outspoken awareness of and interest in processes of growing older or in the life course. But there is a hidden and rarely acknowledged specificity inherent in much research in this discipline: a large fraction of empirical research in social psychology, at least about attitudes and representations, is done with the most accessible category of experimental subjects, i.e., with students, who represent quite a specific age group as well as a set of rather specific locations in social stratification. Little is known about the impact of this double background specificity on the results and scientific knowledge in this discipline. Two transitions have attracted the attention of social demographers, the first from adolescence to adulthood and the second the end of life (mortality).

There are, of course, many conceptual differences that may constitute as many difficulties for mutual understanding and cooperation. Let us only mention one example: the weight that different social science disciplines usually attribute to biology vs. environment (or nature vs. nurture in a more traditional formulation). While psychology has largely put aside earlier apprehensions with respect to close contact with biology, sociology and even more political sciences or social and cultural anthropology have up to now maintained a greater distance ; demography is hard to locate on this dimension, but would certainly have little hesitations to be situated near psychology, and potentially event could stretch its interests as far as to reach not only psychology or sociology, but also biology in the sense that it is currently interested in biologically structured events like birth and death. This basic opposition has a close relative in the difference between internal and external explanations of the « socialization vs. institutional channeling » variety (e.g., concerning the probable impact of age-normative conceptions vs. context or environmental conditions). Confronted to such differences in basic assumptions that characterize the often implicit scientific cultures of different disciplines, interdisciplinary

\footnotetext{
${ }^{10}$ The current French expression is « analyse démographique des biographies » and has nothing to do with the qualitative study of biographical reconstruction that sociologists might have in mind.
} 
collaboration needs above all the renouncement of rigorous a priori stands and a pragmatic curiosity for the other disciplines' way of looking at things. Another important and potentially dividing difference concerns the distinction between factual and representational aspects that may be highlighted by the far-reaching attachment to statistical description by demography on the hand and the heavy emphasis of most of social psychology on individual and collective representations, on the other. If we push this line of thinking further, there are of course situations where it may become very difficult to find common ground between disciplines, like psychology and demography, because they are normally interested in too different topics but then, we are also leaving the array where interdisciplinarity really makes sense.

\section{Pathways to interdisciplinarity}

Beyond such unavoidable practical questions and their solutions, whose importance must not be underestimated, we must also think about more theoretically grounded pathways to real interdisciplinarity. In this section, we wish to propose three such routes for practical exploration: direct theoretical linkages between concepts of different disciplines, identification of formal characteristics of life courses that may acquire similar meanings for different disciplines, and specific substantial themes that may link different disciplinary outlooks due to their transversal relevance. Our presentation will necessarily remain abstract, with only limited illustrations, as our aim cannot go beyond sketching some promising directions; their exploration is yet to come, but hopefully, this outline can provoke some fruitful discussions that help us progress in this sense. We feel moreover that systematic scrutiny of the extant literature would produce a wealth of examples that have already arisen out of research practice. Our proposal is probably little more than a possible systematization of thoughts already present in our field.

\section{Theoretical linkages}

A first possible pathway to the construction of interdisciplinarity in life-course research consists of creating theoretical linkages between concepts of different disciplines. If this is not an explicit part of our everyday practice when doing research, it is often implicitly present. If we take the example of the relationship between sociology and social psychology, we may say that many - perhaps all - sociological hypotheses located on the micro-interactional level and concerning behavior of individuals and groups are based on implicit assumptions of social- 
psychological mechanisms relating the (sociological) concepts used. The most trivial such mechanism is some kind of social rationality, be it along the lines of rational choice theory or according to more complex paradigms. Less trivial examples are social comparison, social learning, the pursuit of social recognition, reciprocity, and advantage, or conformity to social norms. Another, quite different mechanism of that kind would be the one operating the transformation of internal into external attribution in the course of social interactions leading the implied actors to realize that each of them is not alone to experience a given problem but that there is a social category of people with whom they share the problem in question (classical example : the formation of the labor movement, and social movements more generally), and the personally « alleviating » consequence of such processes of collectivization of subjectively felt problems. Many hypotheses about social behavior, e.g., concerning biographical decisions with a view to social mobility, currently assume the functioning of such mechanisms without normally making them explicit, even less testing them. Similar relationships may exist or be developed between other disciplines.

A slightly different example is the formulation of direct interdisciplinary hypotheses, i.e., hypotheses linking dimensions «belonging » to different disciplines. Stating more explicitly Baltes' $(1987,1997)$ thesis of contextuality in psychological development directly leads to such hypotheses, for instance in postulating how structural locations of individuals (in the larger social structure, in their family, in one of their peer groups) explain elements of their identity formation, ways of psychological or interactional styles, etc.

\section{Formal aspects of life courses: trajectories, stages, transitions and events}

We know from research that life-course transitions (such as entering or leaving school, entering professional life or parenthood, marriage, divorce, retirement, moving into nursing homes in old age) have a great significance for individual identities and for the connection between people and institutions. The stages and transitions of life courses are significant in terms of cognitive abilities, representations of the self, relations with significant others and with the institutional and the societal order. Four current concepts are directly related to any processual perspective on the life course: trajectory, stage, transition and event; they are central for the understanding of human action, relatively common to various disciplines, and may therefore constitute another inroad to facilitating the construction of interdisciplinary cooperation. 


\section{Trajectory}

The meaning of trajectory can be defined as "model of stability and long-term changes" (George, 1993) or "sequence of profiles of insertion" (Levy, 2001). In this sense, the notion of trajectory is mainly used to describe the movements or developments occurring during the whole span of life, i.e., all that takes place between the two ultimate life boundaries - or, in our context, transitions - that are birth and death. If this explication remains especially close to sociological use, one finds a similar one in social psychology where trajectories are conceived of as all the movements of an individual in the social space (see among others Viaud, 1999: 80) and in social demography with the notion of biography (Courgeau \& Lelièvre, 1989: 56). ${ }^{11}$ On a more formal level, we may view trajectories as composed by a sequence of transitions (change) and stages (stability).

Cognitive-developmental psychology proposes an in-depth analysis of the models of change and stability in the long run (life span). The idea of the integration of a lifelong trajectory results from the reformulation of the concept of development. The principle of a definite succession of stages in a classical structuralist perspective is completed by that of a sequence of compromises and settlements (growth, maintenance/resilience, regulation) arising from heterogeneous resources (biological, social, cultural). This, considered under the angle of individual development (or ontogeny) and cognitive capacities in particular, contributes to shaping an individual trajectory.

Baltes and Schaie (1976) discuss cohort effects on cognitive performance. Such differences were often confounded with age effects. These results justify the distinction of typical trajectories that correlate strongly with institutional influences and societal transformations while these may in turn affect cognitive performance. Baltes (1987) discussed the relative regularity of processes of change during the first ages of life. Baltes interpreted these results by stating that the social fabric is more solid, substantial and homogeneous during childhood than during adulthood, the latter showing less regularity due to a greater variability of situational factors. Moreover, one could add that the more relevant influences of biological nature during childhood (maturation etc.) imply more regularity of that section of the developmental trajectory.

\footnotetext{
${ }^{11}$ We should note that in some contexts, as here, «biography » is practically synonymous of « life course » whereas in others, the distinction of these two concepts is almost as important as that of sex and gender in gender studies, with « biography» meaning the narrated, principally self-accounted history of an individual, and «life course » the factual unfolding of life as it can be registered by an outside observer (e.g., the Research Committe Nr. 38 «Biography and Society » of the International Sociological Association is clearly interested in biographical research in the sense of this distinction ; cfr. Rosenthal \& Köttig, 2004).
} 
The shift to a social-psychological and sociological perspective on this question happens in the first place by considering the principle of "linked lives" formulated by Elder (1974): trajectories of the individual members of the same primary group (family, friends, workmates) are interdependent. For instance and in principle, it is necessary to take into account the trajectory of the father and the mother of any individual to understand the logic underlying his or her trajectory. In sociological research, this principle is widely applied, notably in research on strategies of social mobility, socialization, domestic functioning, etc. The same principle could bring important results in interdisciplinary research.

In order to build a more complete model, it is advisable to add institutional, historical and geographical dimensions (Kohli, 1985; Elder, 1985; Mayer \& Schoepflin, 1989; Heinz, 1992) to these individual and relational factors. Ideally, the ambition of such a global model would be to capture and interpret the interdependences between these various developmental dynamics. In practice, however, one often prefers to distinguish specific trajectories (marital, professional, health-related, residential) within the global trajectory. ${ }^{12}$ This raises two important questions: on the one hand we need to know how to take account of the mutual influences between these particular trajectories instead of studying them separately. On the other hand, is it after all possible and/or desirable to merge the separate trajectories into a unique global trajectory?

In the perspective of modeling multidimensional trajectories, Abbott (e.g. Abbott, 1992), a historian and sociologist working on both the empirical and theoretical level of trajectories, proposes a "narrative" approach where the notion of narration is substituted to that of causality. According to Abbott one of the major problems of research concerning trajectories lies in the fact that one is mostly confronted with a variety of sequences of events occurring at different speeds. These multiple temporal horizons constitute a theoretical barrier that prevents researchers from raising formalized stories beyond the "simplistic" analyses of stage process (stories which develop relatively independently) and sequences of rational actions. The possibility of matching sequences of events occurring at various speeds might prove very useful for life-course research. The study of life courses might require the integration of seemingly quite heterogeneous dimensions in a unique interpretational model. Ontogenesis does not simply follow a linear succession of ordered stages. Thus trajectories result from the interaction of various factors of different kinds, such as biological, psychological, relational and institution-

\footnotetext{
${ }^{12}$ One can distinguish the interdependences between processes belonging to different spheres in the life of an individual, or between processes which concern an individual and his significant others, or a process which concerns an individual and a transforming context.
} 
al ones, all probably occurring at different paces and with different impacts on the life course. This fact raises important theoretical and methodological questions and surely requires an interdisciplinary collaboration.

\section{Stage}

In sociology, demography, social psychology, psychology as well as in other disciplines, the notion of stage refers to a life period of variable length, characterized by a relative stability and often something like "balance". At the very least and on the most abstract level, a stage can be defined as a "stable state between two transitions." This definition is rather descriptive and may constitute an empirical cut-out of reality based on criteria defined beforehand. Various terms (episode, state, phase, etc.) are based on a similar logic or similar conceptions across the disciplines. At times, the duration of a stage offers a better insight.

Jean Piaget has greatly contributed to the definition of the concept of stage, especially in psychology. He defines stages as relatively long periods resting on the same underlying structures and equilibrium states. ${ }^{13}$ In cognitive developmental psychology, neofunctionalists (or neoPiagetians) and contextualists have reconsidered this concept by means of notions such as "equifinality" (Kruglanski, 1996) and "testing the limits" (Baltes, Lindenberger \& Staudinger, 1998). Neostructuralists have maintained certain Piagetian principles and added the following modifications: (1) the redefinition of cognitive structures (other structures than Piaget's "logico-mathematical" ones), not necessarily seen as universal; moreover, cultural and linguistic factors are also considered; (2) a stage is now defined by an upper cognitive limit, rather than by certain behaviors in different situations; the upper limit moves during ontogenesis, hence, maturation and aging are of chief importance; (3) individual differences and characteristic patterns of individual development are considered; (4) it is assumed that affective and social development are similar to cognitive development. Moreover, the notion of stage has been extended and applied to adult life (Labouvie-Vief, 1980, 1982; Edelstein \& Noam, 1982; Pascual-Leone, 1983; Riegel, 1976; but see already Erikson, 1950).

In social psychology the concept of stage is used to refer to bases of retrospective biographical memories (McAdams, 1993, 1999). However, in many applications of research, the Pia-

\footnotetext{
${ }^{13}$ In most disciplines, the concept of stage, even if conceived as an element of a continuous process, is not inherently linked to notions of finality and universality although these notions have often been intimately associated with the definition of stage. This misconception has been strongly criticized, especially by anthropologists.An important example of such a debate about implicit and scientifically unfounded directionality assumptions on a supraindividual level has concerned modernization theory.
} 
getian conception of stage has been maintained. Moral development, as conceived by Kohlberg and his followers (Turiel, 1983; Gilligan \& Attanucci, 1988), has kept the universal deterministic flavor. However, this conception has been criticized for theoretical and methodological reasons (Emler, 1999; Tostain, 1999).

In social demography, the concepts of episode or phase are usually used to refer to welldefined life periods (e.g., employment phases and phases of professional inactivity for women). Sometimes, the term of age is used to designate a broader phase of the life course (e.g., adult age). ${ }^{14}$ However, the application of the term of stage in a sense close to the Piagetian tradition seems to be recent (De Bruijn, 1999); its universalistic and deterministic features are mostly avoided. Instead, emphasis is put on human agency. Furthermore, the deterministic feature of a stage is opposed to the stochastic character attached to events.

In sociology, the concept of stage refers to a stable state of various duration. The social constraints and normative expectations typical of each stage are generally emphasized. Historically, in a macro-sociological perspective, models directly relying on the conception of stage (Comte, Marx, Spencer, Parsons) have been strongly criticized because of their evolutionist, linear and deterministic features. In a micro-sociological perspective, the notion of stage has been applied to the description of family development and, of course, to individual life courses where it is sometimes used to designate age-groups (e.g., adolescents, middle-aged etc.), sometimes also categories defined by a specific institutional participation (like preschoolers, employed, retired, etc.). Close terms such as period are often used to avoid the restrictions of the more assumption-loaded term of stage.

\section{Transition}

Across disciplines, the concept of transition refers to the idea of change: change from one state or situation to another, from one life period to another, from one status or role to another. In this vein and by inverting the above definition of stage, we might define a transition as the (short) period of change relating consecutive stages. More precisely and less circularly, transitions are moments within a particular trajectory characterized by accelerated changes, compared to the relative stability of stages. Examples of transitions are quite different according

\footnotetext{
${ }^{14}$ For some researchers interested in fertility issues, the reproductive age (career) might be divided in several phases or stages, each of them characterized by a specific knowledge, a childbearing motivation, and a style of decision making (Forrest, 1988): (1) before first sexual intercourse; (2) from first sexual intercourse to marriage; (3) from marriage to first birth; (4) first birth to desired family size; (5) from family completion to mother's menopause.
} 
to the type of change considered: change from a limited to a broadened capacity of information processing (possibly leading from one type of reasoning to another), from single life to marriage, from adolescence to adulthood, from the status of an employee to that of a manager. Three characteristics attributed to the concept of transition seem to be rather consensual across the different approaches: (1) a transition always refers to its outcome, a novel status of relative stability (in psychology often characterized by a higher equilibrium or stability, but not in social demography or sociology); the different approaches, depending on their objects of study, their objectives and their theoretical assumptions, do or do not have precise criteria allowing an evaluation of a transition in terms of the developmental progress it conveys; (2) transitions are processes more or less clearly limited in time (although they may have longterm consequences); (3) most often, the concept of transition is applied to the changes in an individual life course, but it appears also in notions of social transition, collective transition or even demographical transition.

Defining a phenomenon as transitional can not be done in an absolute way since by definition, a transition relates a state "before" to a state "after". The use of the term depends on the extension and on the specific processes implied by the transition and may sometimes be a specific way at looking at an object rather than this object's inherent characteristic. For instance, adolescence can either be qualified as a transitional stage, in particular in a perspective of development from childhood to late adulthood (Durkin, 1995), or as a life stage in itself, with its own developmental tasks, at the end of which the transition to adulthood takes place (Erikson, 1950).

Three related concepts, each referring to a particular kind of transition, are: (1) "revolution" (Mounoud, 1982), which refers to a discrete transition, to the emergence of a new "structure d'ensemble" and thus does not apply to the acquisition of a new isolated capacity; (2) "turning point" (Gotlib \& Wheaton, 1997), which refers to a transition (or perhaps more frequently to an event) that implies a change in the orientation of a trajectory and not just a mere confirmation of this trajectory by a transition that fits into a general pattern; (3) "social mobility", upward, downward or horizontal, which is only related to transitions that affect the social status of a person, mostly implying an increase or a reduction of his economic, social or cultural capital (in the case of vertical mobility).

A number of theorists have attempted to apply to the study of individual transitions the mathematical "catastrophe theory" (Thom, 1975) and the concept of "bifurcation" (e.g., van der Maas \& Molenaar, 1992). Such a modeling approach has the advantage of combining quanti- 
tative with qualitative changes. For instance, a series of small quantitative changes can eventually lead to an abrupt transition, resulting in what proves to be qualitatively very different from the preceding periods.

Although commonalities of the concept of transition exist across disciplines, each discipline differentiates its approaches to and uses of the notion of transitions. Social demography and sociology share a focus on the study of the effects of various parameters - sociodemographical (e.g., fertility, life expectancies, migration, social and geographical mobility) or institutional (compulsory school, labor market, retirement system, etc.) on the occurrence, timing and variability of transitions (Hogan, 1981; Rindfuss, Swicegood, \& Rosenfeld, 1987; Settersten \& Mayer, 1997). In social psychology, the same transitions are most often conceived of as independent variables whose effects are studied (e.g., in studies interested in the effects of particular transitions on social representations, Viaud, 1999, and self-concept, Hagestad \& Neugarten, 1985; Havighurst, 1972; Kling, Ryff, \& Essex, 1997). Developmental cognitive psychologists are more interested in explaining the mechanisms and explanatory factors of transitions characterizing the individual cognitive development (de Ribaupierre, 1989). In a Piagetian perspective, these mechanisms are described as depending on processes of maturation, cognitive conflict, equilibration and the interaction with the social environment. Here, transitions are usually conceived as dependent variables and at a more microscopic level than in sociology or social demography.

The idiosyncrasies of the various disciplines have not hindered interdisciplinary work. For instance, some researchers in social psychology are interested in life choice orientations (which directly influence normative transitions) through the analysis of the impact of values or of social identities on transitions considered as dependent variables (Cinnirella, 1998). Furthermore, acknowledging the role of the social environment and the individual behavior on cognitive transitions requires that the disciplines interact and provide complementary contributions to the study of the life course. In this regard, Doise \& Mugny (1997) illustrate the facilitating role of social interactions and social marking in the resolution of Piagetian tasks. Indeed, this line of research provides insights into the influence of social dynamics on the transition from one cognitive stage to another, and it also shows how these dynamics can be studied with an interdisciplinary approach. Another possible link between social psychology, sociology and social demography is their common interest as to how transitions are regulated by normative representations as well as by life experiences and their interpretation on the one 
hand, and on the other hand how these are shaped by changes in their socio-historical background (Neugarten, Moore, \& Lowe, 1965; Elder, 1974).

\section{Event}

According to a general definition, an event is "what happens at a given time in a given place" (Encyclopedia Universalis, 1999). This notion is ambiguous since some events are characterized by their singularity and unexpectedness, others by their regularity and expectedness. This ambiguity holds for several events of the life course. For instance, life events (such as a second marriage) can be considered as unique at the level of individuals. They "are particular moments in a particular time and place, complete with particular characters, actions, thoughts and feelings" (McAdams, 1993. p. 258). But they can also be characterized by their repetition at the level of a social group or a population. In this case, the event could be defined as a "fact which concerns an individual and which affects the structure of populations and its development" (Pressat, 1979: 68). Scientific disciplines could be distinguished depending on the emphasis they give either to the singularity or to the expectedness of an event. In this way, one can oppose, e.g., socio-demographical and socio-psychological approaches. ${ }^{15}$

Social demography emphasizes regularity (i.e., repetition). This is achieved by: 1) describing the event (e.g., marriage, birth, death); 2) considering this event as part of a collective phenomenon (e.g., nuptiality, natality, mortality, mobility and migration); 3) using quantitative methods for this description; 4) eventually predicting the event with the tools of demographic projection. The meaning of the event is defined on the basis of its statistic regularity. For instance, in the frequently cited paper titled "The changing meaning of cohabitation and marriage" of Manting (1996), the meaning of cohabitation or marriage in the Netherlands is not derived from Dutch values and opinions about these events, but from the development of partnerships starting as cohabiting unions and to the marriages of cohabiting couples. Entry into cohabitation was rare during the seventies, and cohabiting couples rarely married. However, this kind of unions became more and more frequent during the eighties and nineties, as

\footnotetext{
${ }^{15}$ We do not explicitely integrate the specific area of life-event research that has developed mainly in social medecine and psychiatry, but would like to mention it as an interesting source of empirical findings that strongly underscore the relevance of specific and especially of singular events for subsequent periods of life. At the same time the diversity and sometimes even contradictory character of these findings point to the necessity of explicitly taking into account conceptual tools of various disciplines, particularly with respect to the non-reductible complementarity of objective and subjective features (i.e., their personal meanings) of such events if we are to understand their consequences.
} 
cohabiting couples married more often. According to Manting, the role of cohabitation evolved from a substitute to marriage to a preliminary period before marriage.

Social psychology insists on the singularity of events. This is achieved by assuming that a person defines an event and then by focusing the research on the possible disturbance brought about by the event on the individual identity. The event represents a mark between a "before" and an "after." Because the event is defined by the individual (or the group), social psychology insists on its subjective character. For example, the concept of attribution captures the idea that various degrees of causal relations could be established between behaviors and "reinforcements" (e.g., the interpretation of an event as positive or negative; Deschamps \& Beauvois, 1996). Attribution leads to the notion of allocation (i.e., how persons can explain events in their everyday life). Here, a distinction is made between "internal and external causalities." Internal causality means that an individual attributes the event to him- or herself, external causality that he or she names an external, environmental cause for the event. The current hypothesis is that the type of attribution performed by the individuals has major consequences on their future behaviors.

Sociology and social demography have a certain extent of common ground as far as the definition of events is concerned, especially of events perceived by the individuals as intrinsically motivated (e.g. marriage). Furthermore, sociology also insists on the expectedness of the event (normative life events vs. stressful events). In the case of stressful events, the interest lies especially on their "consequences" for the life courses.

In cognitive psychology, the event is mainly apprehended as a stimulus or a novel phenomenon or a disturbance the individual has to react to, and is thus usually defined by the experimenter (i.e., simulated and manipulated as an independent variable). Typically, the research is not interested in the event itself, but in the individual reaction to the event understood as a stimulus.

The meaning of the term "disturbing event" is sometimes only slightly different in each discipline. In social demography, the succession of events is addressed by most researchers. The questions circle around the effects of a perturbing event on the occurrence of other events (e.g., the effect of migration on marriage; Courgeau \& Lelièvre, 1989). In this perspective, disturbing events are similar to the "turning points" in social psychology or sociology. These events coincide with trajectory changes ("bifurcation" as described in sociology by de Coninck \& Godard, 1989 is a closely related concept). An example of a turning point (or event) 
is a disabling illness or accident and its eventual consequences in the form of a deep and global reorientation of life. Events occurring in a "coherent" way within the overall orientation of a trajectory can be opposed to turning points. In sociology and social psychology, disturbing events are unexpected and often considered as "stressful", at least potentially. These events can be directly related to persons (e.g., illness) or to external events (e.g., death of a significant relative, parents' divorce, collective dismissal). In this last case, the interest lies in the amount of stress caused by the event depending on its social context and meaning.

In the present context, a special mention should be made of the research field of life event research (Dohrenwend \& Dohrenwend, 1982; Brown \& Harris, 1989), an area of study that rests on the basic hypothesis that unforeseen events in the life course can alter its further progress and have more or less important consequences on the persons who experience them. It is multidisciplinary since at least social psychiatry, social psychology and sociology are being mobilized by life-event researchers, and it represents one extreme, "empiricist" option of interdisciplinarity in that it is often practiced with particularly little theoretical preconceptions, at least concerning the nature of significant events and of the mechanisms that relate them to their possible effects on the life course. Even though it seems to be rarely integrated by more outspokenly life-course or life-span oriented research, some results of this line of research confirm basic tenets of life-course research precisely because of its atheoretical conception, such as the finding that the positive or negative value of life events cannot be found in themselves, but depend strongly on their interpretation by the concerned actors and their environment, that their positive or negative effects depend moreover on the coping resources concerned actors can mobilize, and that the abruptness of their occurrence may be as consequential as their qualitative noxiousness (which reminds one of Durkheim's notion of "happy crises" that may create, according to his hypothesis, as much anomy as unhappy ones).

A disturbing or stressful event may act as a turning point. In a rigorous conceptual perspective, we may even ask whether the notion of event should be located on the same level as the other three terms, trajectory, stage, and transition. We might also consider events to be potential transitions (of positive or negative social value) depending on the possibilities of lifecourse actors to cope with them. Finally, what is an event may vary as a function of the finegrainedness we chose for our interrogation: divorce can be considered as en event, unique and momentary, e.g., in a demographic analysis. But it can as well be studied as a rather long-term process in which the formal act of legalized separation is only one relatively late step, and maybe not even the most consequential one. 


\section{Transversal substantive themes - contents of this volume}

A third line of interdisciplinary collaboration can be found in transversal themes or research dimensions that appear in several disciplines, even though they are typically approached differently by them. In a way, the formal aspects treated in the previous section - especially transitions and events - have also very substantive meanings; they can therefore also be subsumed under this heading and may be considered as first examples. Examples of other such dimensions are, in an arbitrary and imperfect order, gender differentiation, subjective vs. objective aspects of the life course and their relationships (« subjective» including questions of experience, representations, identity, projects, cultural models, etc.), agency vs. structure in and about life courses, linked lives, interinstitutional links forming life-course regimes. We may also think of thematic fields such as gerontology, which, by definition, is inter- or at least multidisciplinary. Various academic departments (especially human development and family studies) as well as centers of gerontology typically count among their members scholars from different disciplines, such as demography, sociology, psychology, biology, kinesiology, nurse practice, health policy, communication science, social work, educational sciences, ecology, counseling, anthropology, philosophy, theology, etc. ${ }^{16}$ It is, however, certainly not sufficient to have different disciplines attached to the same organizational unit for interdisciplinarity to develop, even if this can become a favorable condition. Direct collaboration is a much more promising situation, especially in projects explicitly designed to be interdisciplinary from the outset.

We have chosen to organize this volume around four such themes: agency and structure, transitions, biographical re-construction, and methodological innovations. The first three themes are substantive and take up some of the transversal lines we have sketched earlier in this essay. The disciplinary origins of their authors reflect that they are not yet equally treated in the disciplines we solicited for this volume.

\footnotetext{
${ }^{16}$ This is often possible because faculty members hold joint or courtesy appointments. Hence they belong to distinct departments and only occasionally collaborate on common projects. This sort of institutional structure, although representing progress, is not the ideal environment for fostering common research grounds. The sharing of information is undoubtedly facilitated by centers of this kind. However, interdisciplinarity, as we claimed before, aspires to deeper linkages among the disciplines. This is again reflected by the lack of Ph.D. programs in gerontology. To our knowledge, various postgraduate diplomas exist in gerontology, but only few Ph.D. titles; the same seems to hold for life-course studies.
} 


\section{Agency and structure}

Agency and structure has become an important issue in sociological debates since the $80 \mathrm{~s}$, perhaps less so in other disciplines. The first chapter takes up this theme, locating it clearly in the substantive area of life-course research.

Settersten and Gannon focus on the joint impact of social structure and human agency, in proposing a life-course model of agency within structure. They consider how individuals actively create their own lives and maximize their own development within parameters set by their social worlds (some of which may constrain them, and some of which may enable them), and how individuals interact with, and even make proactive attempts to alter, those worlds. Several examples from three different life periods are provided: childhood and adolescence, early adulthood through midlife, and old age. The tension between the theses of standardization or de-standardization of life courses is reconceptualized as not to be resolved by one thesis winning out over the other, but as being acknowledged to be complementary processes, loosely associated with agentic and structural dimensions of the life course.

Marshall tackles the topic of structure and agency first by reviewing the literature for explicit and implicit definitions of these two crucial terms and by revisiting, in an autobiographic return, some earlier results of his comparative study of aging communities. He comes up with a theoretical model containing both aspects and recovers Clausen's concept of planful competence as one straightforward way to conceptualize life-course agency. Like other contributors, he reminds us of important complexity that must not go unnoticed in life-course research, especially a necessary differentiation of the concept of identity, and expresses hope for a rejuvenating theoretical input by European life-course researchers.

Lüscher looks into a specific and often neglected aspect of social relations, especially intergenerational relations, tending to rehabilitate ambivalence as a basic psychological ingredient for sociological analysis. This is a timely hint at the fact that the links between the lives lifecourse analysis is bound to take into account are not just arrows on network charts, but real social relations with their affective depth and complexity. In fact, the concept of linked lives is extremely important, but still awaits theoretical and empirical development, not only concerning the type of people that can lead linked lives (like successive generations or partners in a couple), but also referring to the nature of their relationship (besides the emotional valence, 
their strength is also a variable that merits more consideration: are linked lives based only on strong ties or may weak ties also play role?).

\section{Transitions}

While life-course research makes a strong argument for considering the whole life span instead of limiting its interest to specific parts of it (especially single phases), specific aspects of life courses may be more fertile for research than others. Transitions are particularly revealing of life-course dynamics on several accounts and are at the center of four contributions. Although, for the time being, they seem to be principally investigated by sociologists, they look promising for psychology and social psychology as well.

Mortimer and her co-authors attempt to disentangle the respective influences of social structures and individual agency, in focusing on the issue of educational attainment in the transition to adulthood. Some scholars highlight cultural values, normative timetables, stratification processes, and institutional career lines as determinants of the contents and pacing of role changes through the life course. Others, in contrast, emphasize the exercise of human agency as a central causal force in shaping the life course, including the expression of values and identities, self-regulative processes, decision-making, and striving to achieve personal objectives through goal selection, strategic planning and action. Mortimer et al. focus on the interactions existing between these two dimensions. Using data from the Youth Development Study, a 15-year panel study of work experience and the transition to adulthood, they show that early goals and values are linked to work behavior during high school, which in turn has predictive power with respect to subsequent trajectories of work, schooling, and educational attainment. The study presents promising ways for opening the "black box" of the processes and mechanisms, both structural and agentic, underlying life paths of transition to adulthood.

With an autobiographical twist, Furstenberg takes up the thesis of many life-course researchers that chronological and sequential «order» is important, that deviation from this order (like being out of schedule) constitutes a problem and is bound to provoke undesirable outcomes. Reviewing recent analyses, he shows that results seeming to confirm this somewhat structuro-deterministic idea are in fact less than convincing and remain open to contrary, more optimistic and « agentic » interpretations ; according to his argument, « life-course deviance » may as well lead to growth in life-course managing capacities. A major role in determining 
whether non-normative trajectories, be they out-of-time or out-of-order, become problematic for later stages in life seems to be reserved to social and psychological resources and thus index the structural environment of « life-course passengers ».

Looking into The Secret of Transitions, Bird and Krüger develop a strong argument about the danger of substantive blinders brought along by methodological and conceptual reductions, for example in the case of the study of life-course transitions by help of event-history analysis. They advise us not to forget the complexity of life courses in the double sense that they are made up of several parallel and related trajectories and that transitions belonging to different trajectories may interact without necessarily being synchronized. Moreover, even in one trajectory, transitions are often multi-layered and last longer than their treatment as « events » would suggest. On the basis of empirical examples concerning sex-differentiated life courses, they propose a timely typology of transitions based on their sociodynamic features that can help avoid excessive reduction of social complexity on the conceptual and interpretive level.

\section{Biographical Re-construction}

Life-course and biographical analysis (in the sociological, not the demographic use of the term as we pointed out before) have long been considered to be strangers ignoring each other - if not hostile antagonists - especially in some European research traditions. Heirs of the fundamental debate between the "two cultures » in the social sciences, life-course analysis is often purported to be positivist, explanatory and quantitative, biographical analysis constructivist, interpretive, and qualitative. While this divide still exists, it has become questioned by more recent pragmatic positions, preferring mixed methodologies (Tashakkori \& Teddlie, 1998) and quali-quanti triangulation (Erzberger \& Prein, 1997) to methodological fundamentalism. Even though this debate has probably raged more in sociology than in most other social science disciplines, it is highly relevant for all of them, especially in the life-course area. The contributions concerning biographical reconstruction are instructive in this respect, the first relating identity change directly to life-course transitions, the second approaches directly and empirically the crucial theme of biographical memorization, and the third is an example of interpretive work in a discipline that has heretofore privileged quantitative approaches. Biographical accounts have become a field more currently shared at least by social psychologists and sociologists. 
In a chapter relating this part of the volume to the previous one, Emler presents in a social psychological perspective how identity shifts take place during life transitions. A first section is devoted to the presentation of the classical view of cognitive development (Piaget, Kohlberg) as abrupt qualitative changes resulting in a succession of qualitatively different stages. Then social identity is defined on the basis of self-categorization theory, taking into account the relationships between social identity and social networks. One central issue of this chapter is to understand if identity development is a gradual process or if it corresponds to a stage model with sudden and discrete changes. Based on different examples in the areas of political identity and changes in personal relationships, it opens new directions of thought and research in the study of shifts of identity across life transitions.

Perrig-Chiello and Perrig bring together different important psychology fields in the study of personality across the life span: auto-biographical memory, well-being and personality traits. Psychologists have developed different theories on how the individuals construct their autobiographical memory. This chapter presents empirical evidence showing that personality traits like neuroticism and extraversion have a consistent relationship with recollection of autobiographical episodes and well-being. Results also indicate that the impact of personality traits may be more important than positive or negative life events. These results raise important questions about how individuals adapt and reconstruct life events across their life course, and how subjective experiences, and in particular personality traits, may have objective effects on life trajectories.

McAdams is a personality psychologist who has developed a narrative approach to identity across the life span - a highly welcome complement to the personality trait approach. Building on the idea that identity is constructed in a continuous process across the life course, he shows that life stories are developed by individuals following distinct "story lines". For example, he shows that life stories may be narratively organized as contamination (good to bad) or redemption (bad to good) sequences. The various antecedents and consequences of these types of life stories are described on the basis of empirical examples. A promising development of this approach is the possible link between these life stories and the cultural context in which they are expressed and constructed. 


\section{Methodological innovation}

Methods of analysis have a peculiar role in our thematic field, especially so quantitative methods, ${ }^{17}$ in the sense that they are not very numerous and well-known, based on technical and also conceptual implications that have to be scrutinized all the more seriously for their implicit assumptions and basic logics for the interpretation of results as they are practically all imported from more or less distant fields or disciplines (this is probably the most transdisciplinary sector in life-course research !), and the danger of one method dominating the field and the substantive outlook of researchers merits particular attention (one obvious candidate for becoming a «hegemonic method» in quantitative life-course research is event history analysis, with optimal matching a newcoming junior competitor that remains at the margins of the arena for the time being). Therefore, we find it useful to contribute to methodological diversification with a set of promising and innovative contributions presenting methods for exploration and analysis that have not yet made decisive inroads into this area. The three chapters of this volume nicely complement each other, due largely to the different, but sometimes converging and highly complementary, research fields of the authors. Francesco Billari's applications are mainly in demography, especially in the research fields of fertility and transition to adulthood. Michel Oris, a demographic historian, and Gilbert Ritschard, an econometrician, have been collaborating for several years on projects requiring both an acute historical sense for the analyses of demographical issues and advanced analytical tools which statistically address the theoretical questions of interest. The work of Jack McArdle, a psychologist, has been focused on age-sensitive methods for psychological and educational measurement and longitudinal data analysis. Together, the four authors provide an exceptional overview of novel life-course methodologies of great potential and invite us to think about future developments. Each chapter briefly summarizes the state of the art of its research field before heading into the most recent advances and promising extensions.

In his contribution, Billari compares the two major approaches of quantitative methods used in life-course research, the event-oriented and the holistic approach. The former quantitative approach is largely represented by the freshly popular analytical techniques of event history (or survival) analysis and also newer techniques stemming from program evaluation work.

\footnotetext{
${ }^{17}$ Given their greater openness, qualitative methods do not seem to present the same potential of substantively orienting research and of blinding it towards phenomena for which the methods we use have no outright provision. Even though, a similar danger could be related to an exclusive use of qualitative methods, especially if accompanied by a conceptual reduction of the range of research questions to those qualitative methods can answer.
} 
The latter approach is mostly represented by techniques used to analyze any sequence of events and trajectories over the whole life course, and prime among these is optimal matching analysis. Both approaches are used in turns to answer different but complementary life-course research questions. The event-oriented approach is often used in a causal perspective of analysis, and the author describes all different kinds of causal factors susceptible to affect the occurrence of an event. The holistic approach is adopted to analyze different factors influencing trajectories. Billari then invites the reader to consider that the two perspectives are couched in the two statistical cultures of data versus holistic modeling discussed in the very influential paper of Breiman (2001). The data modeling culture naturally pairs up with the event-oriented approach, the algorithmic modeling culture with the holistic approach. Billari provides several examples to clarify his arguments and to illustrate how the two traditions and approaches complement each other in addressing life-course phenomena.

The chapter by Ritschard and Oris discusses how the fields of historical demography and contemporary demography promisingly joined forces, especially under the life-course research paradigm. They discuss three analytical approaches and illustrate them by relevant examples. First, event history analyses are again taken up, but this time in relation to very recent advances allowing to account for shared heterogeneity or frailty in the presence of multiple groups. The combination of event history analysis with multilevel modeling will undoubtedly witness much success in several research fields. The second set of statistical techniques presented by the authors is that of Markov transition models used to analyze state sequences, or individual trajectories across quantitatively and possibly qualitatively different phases in the life course. The categorical changes can be dependent of observed or latent covariates and differ with respect to their temporal expression, or lags. Again, this technique is progressing at a quick rate and the range of its applications is growing accordingly. The third set of analyses consists in longitudinal data mining techniques based on an induction tree approach. While more exploratory in nature than the previous two techniques, induction trees ideally describe the change trajectories of complex multivariate systems, in which the elements are ordered by importance and predictability power. As illustrated by the authors, this newer set of techniques may complement the other two and add much insight into life-course research objects, over and above what was already learnt with more classical techniques.

McArdle accompanies the reader in exploring a unique data set of cognitive measures obtained on 7 occasions from 1931 to 1998 on the same individuals. The data are first described 
and observed with respect to their presence as well as absence (i.e., incomplete data). Then individual and group change characteristics are determined and possible predictors of change are tested. Latent growth curve models, a particular application of structural equation modeling, are used to this end, which are known in the educational and biostatistical literature under different names (hierarchical linear modeling, multilevel modeling, random or mixed effects modeling, etc.). Group differences in developmental trajectories are then explored, on an apriori level (via traditional multi-group structural equation modeling) as well as on an aposteriori level (with more recent latent mixture models). Finally, McArdle introduces an advanced class of structural equation models based on previous work in econometrics, biostatistics, and behavior genetics to explore dynamics of change. In other words, we are now invited to examine the data in a non-static perspective, going from description to explanation of change phenomena. The advanced latent difference score models introduced by McArdle represent a very promising set of analytical tools capable of addressing classical as well as innovative theories of change in several research fields.

Finally, in their afterthought chapter, the editors bundle together the novel impulses for fostering interdisciplinary life-course research that can be gleaned from the contributions to this volume and suggest directions for future development. 


\section{References}

Abbott, A. (1992). From Causes to Events: Notes on Narrative Positivism. Sociological Methods \& Research, 20, 428-455.

Baltes, P. B. (1987). Theoretical Propositions of Life-Span Developmental Psychology: On the Dynamics between Growth and Decline. Developmental Psychology, 23, 611-626.

Baltes, P. B. (1997). On the Incomplete Architecture of Human Ontogeny: Selection, Optimization, and Compensation as Foundation of Developmental Theory. American Psychologist, 52, 366-380.

Baltes, P. B., Lindenberger, U., \& Staudinger, U. M. (1998). Life-Span Theory in Developmental Psychology. In R. M. Lerner (Ed.), Handbook of Child Psychology, Vol. 1: Theoretical Models of Human Development (pp. 1029-1143). New York: Wiley.

Baltes, P. B., \& Schaie, K. W. (1976). On the plasticity of intelligence in adulthood and old age: Where Horn and Donaldson fail. American Psychologist, 31(10), 720-725.

Breiman, L. (2001). Statistical Modeling: The Two Cultures. (With Comments and Rejoinder). Statistical Science, 16, 199-231.

Bronfenbrenner, U. (1979). The Ecology of Human Development. Cambridge: Harvard University Press.

Brown, G. W., \& Harris, T. O. (Eds.) (1989). Life Events and Illness. New York: Guilford.

Cinnirella, M. (1998). Exploring temporal aspects of social identity : the concept of possible social identities. European Journal of Social Psychology, 28, 227-248.

Courgeau, D., \& Lelièvre, E. (1989). L'approche biographique en démographie. Revue française de sociologie, 31(1), 55-74.

De Bruijn, B. J. (1999). Foundations of Demographic Theory. Choice, Process, Context. Amsterdam: NethurD Publications.

de Coninck, F., \& Godard, F. (1989). Les formes temporelles de la causalité. Revue française de sociologie, 31(1), 23-53.

de Ribaupierre, A. (Ed.) (1989). Transition Mechanisms in Child Development. Cambridge: Cambridge University Press. 
Deschamps, J.-C., \& Beauvois, J.-L. (Eds.) (1996). Des attitudes aux attributions - Sur la construction de la réalité sociale (Vol. II). Grenoble: Presses universitaires de Grenoble.

Dohrenwend, B. S., \& Dohrenwend, B. P. (Eds.) (1982). Stressful Life Events and Their Contexts. New York: Neale Watson.

Doise, W., \& Mugny, G. (1997). Psychologie sociale \& développement cognitif. Paris: Armand Colin.

Durkin, K. (1995). Developmental Social Psychology from Infancy to old Age. Malden: Blackwell.

Edelstein, W., \& Noam, G. (1982). Regulatory structures of the self and "postformal" stages in adulthood. Human Development, 6, 407-422.

Elder, G. H. (1974). Children of the Great Depression. Chicago.

Elder, G. H. (Ed.) (1985). Life Course Dynamics: Trajectories and Transitions, 1968-1980. Ithaca: Cornell University Press.

Elder, G. H. (1995). The Life Course Paradigm: Social Change and Individual Development. In P. Moen, G. H. Elder \& K. Lüscher (Eds.), Examining Lives in Context: Perspectives on the Ecology of Human Development (pp. 101-139). Washington: APA Press.

Emler, N. (1999). What does principled versus conventional moral reasoning convey to others about the politics and psychology of the reasoning? European Journal of Social Psychology, 29(4), 455-468.

Encyclopedia Universalis (1999). Paris.

Erikson, E. H. (1950). Childhood and Society. New York: Norton.

Erzberger, C., \& Prein, G. (1997). Triangulation: Validity and Empirically-Based Hypothesis Construction. Quality and Quantity, 31(2), 141-154.

Forrest, J. D. (1988). Contraceptive needs through stages of women's reproductive lives. Contemporary Obstetrics Gynaecology, 32, pp 12-22.

George, L. K. (1993). Sociological Perspectives on Life Transitions. Annual Review of Sociology, 19, 353-373.

Gilligan, C., \& Attanucci, J. (1988). Two moral orientations: Gender differences and similarities. Merril-Palmer Quarterly, 34(3), 223-237. 
Gotlib, I. H., \& Wheaton, B. (Eds.) (1997). Stress and Adversity Over the Life Course. Cambridge: Cambridge University Press.

Hagestad, G. O., \& Neugarten, B. L. (1985). Age and the life course. In E. Shanas (Ed.), Handbook of aging and the social sciences (Vol. 2, pp. 35-61). New York: Van Nostrand Reinhold.

Havighurst, R. H. (1972). Developmental Tasks and Education (3rd ed.). New York: David McKay.

Heinz, W. (Ed.) (1992). Institutions and Gatekeeping in the Life Course. Weinheim: Deutscher Studienverlag.

Hogan, D. P. (1981). Transitions and Social Change: The Early Lives of American Men. New York: Academic Press.

Kling, K. C., Ryff, C. D., \& Essex, M. J. (1997). Adaptative changes in the self-concept during a life transition. Personality and Social Psychology Bulletin, 23, 981-990.

Kohli, M. (1985). Die Institutionalisierung des Lebenslaufs. Kölner Zeitschrift für Soziologie und Sozialpsychologie, 37, 1-29.

Kruglanski, A. W. (1996). Goals as knowledge structures. In J. A. Bargh (Ed.), The Psychology of Action: Linking Cognition and Motivation to Behavior (pp. 599-618). New York: Guilford Press.

Labouvie-Vief, G. (1980). Beyond formal operations : Uses and limits of pure logic in lifespan development. Human Development, 23, 141-161.

Labouvie-Vief, G. (1982). Growth and aging in life span perspective. Human Development, $25(1), 65-79$.

Levy, R. (2001). Regard sociologique sur les parcours de vie. In P. Domininicé (Ed.), Regards pluriels sur l'approche biographique : entre discipline et indiscipline (pp. 1-20). FAPSE, UNIGE: Cahiers de la section des sciences de l'éducation, No 95.

Manting, D. (1996). The changing meaning of cohabitation and marriage. European Sociological Review, 12, 53-65.

Mayer, K. U. (2002). The Sociology of the Life Course and Life-span Psychology - Diverging or Converging Pathways? In U. M. Staudinger \& U. Lindenberger (Eds.), Under- 
standing Human Development: Lifespan Psychology in Exchange with Other Disciplines. Dordrecht: Kluwer.

Mayer, K. U., \& Schoepflin, U. (1989). The State and the Life Course. Annual Review of Sociology, 15, 187-209.

McAdams, D. P. (1993). The Stories We Live by: Personal Myths and the Making of the Self. New York: The Guilford Press.

McAdams, D. P. (1999). Personal narratives and the life story. In O. John (Ed.), Handbook of Personality: Theory and Research (2nd ed., pp. 478-500). New York: Guilford Press.

Mortimer, J. T., \& Shanahan, M. J. (Eds.) (2003). Handbook of the Life Course. New York: Kluwer/Plenum.

Mounoud, P. (1982). Revolutionary periods in early development. In T. G. Bever (Ed.), Regression in Mental Development (pp. 119- 131). Hillsdale, NJ: Erlbaum.

Neugarten, B. L., Moore, J. W., \& Lowe, J. C. (1965). Age Norms, Age Constraints, and Adult Socialization. American Journal of Sociology, 70(6), 710-717.

Pascual-Leone, J. (1983). Growing into human maturity: Toward a metasubjective theory of adulthood stages. In O. G. Brim Jr. (Ed.), Life-span Development and Behaviour (Vol. 5, pp. 117-156). New York: Academic Press.

Pressat, R. (1979). Dictionnaire de démographie. Paris: PUF.

Riegel, K. F. (1976). The dialectics of human development. American psychologist, 31, 689700 .

Rindfuss, R. R., Swicegood, C. G., \& Rosenfeld, R. (1987). Disorder in the life course: How common and does it matter? American Sociological Review, 49, 359-372.

Rosenthal, G., \& Köttig, M. (2004). Biography and Society - Reading list. Internal paper of ISA RC 38 "Biography and Society".

Settersten, R. A. (1999). Lives in Time and Place. The Problems and Promises of Developmental Science. Amityville: Baywood.

Settersten, R. A. (2003a). Propositions and Controversies in Life-Course Scholarship. Chap. 1. In R. A. Settersten (Ed.), Invitation to the Life Course: Toward New Understandings of Later Life (pp. 15-45). Amityville: Baywood. 
Settersten, R. A. (2003b). Rethinking Social Policy: Lessons of a Life-Course Perspective. Chap. 7. In R. A. Settersten (Ed.), Invitation to the Life Course: Toward New Understandings of Later Life (pp. 191-222). Amityville: Baywood.

Settersten Jr, R. A., \& Mayer, K. U. (1997). The measurement of age, age structuring, and the life course. Annual Review of Sociology, 23, 233-261.

Staudinger, U. M., \& Lindenberger, U. (Eds.) (2003). Understanding Human Development. Dialogues with Lifespan Psychology. Boston: Kluwer.

Tashakkori, A., \& Teddlie, C. (1998). Mixed Methodology. Combining Qualitative and Quantitative Approaches. Thousand Oaks: Sage.

Thom, R. (1975). Structural Stability and Morphogenesis: An Outline of a General Theory of Models. Reading, MA: Benjamin-Cummings Publishing.

Tostain, M. (1999). Psychologie, morale et culture. L'évolution de la morale de l'enfant à l'âge adulte. Grenoble: Presses Universitaires de Grenoble.

Turiel, E. (1983). The Development of Social Knowledge: Morality and Convention. Cambridge: Cambridge University Press.

van der Maas, H. L., \& Molenaar, P. C. (1992). Stagewise cognitive development: An application of catastrophe theory. Psychological Review, 99, 395-417.

Viaud, J. (1999). Principes organisateurs et représentations sociales de l'économie : genèse et dynamique. Revue Internationale de Psychologie Sociale, 12(2), 79-105.

Wohlwill, J. F. (1970). The Age Variable in Psychological Research. Psychological Review, $77,49-64$. 